\title{
Energy recovery from wastewater microalgae through anaerobic digestion process: Methane potential, continuous reactor operation and modelling aspects
}

Tsapekos, Panagiotis; Kougias, P.G.; Alvarado-Morales, Merlin; Kovalovszki, Adam; Corbière, M.; Angelidaki, Irini

Published in:

Biochemical Engineering Journal

Link to article, DOI:

10.1016/j.bej.2018.08.004

Publication date:

2018

Document Version

Peer reviewed version

Link back to DTU Orbit

Citation (APA):

Tsapekos, P., Kougias, P. G., Alvarado-Morales, M., Kovalovszki, A., Corbière, M., \& Angelidaki, I. (2018). Energy recovery from wastewater microalgae through anaerobic digestion process: Methane potential, continuous reactor operation and modelling aspects. Biochemical Engineering Journal, 139, 1-7. https://doi.org/10.1016/j.bej.2018.08.004

\section{General rights}

Copyright and moral rights for the publications made accessible in the public portal are retained by the authors and/or other copyright owners and it is a condition of accessing publications that users recognise and abide by the legal requirements associated with these rights.

- Users may download and print one copy of any publication from the public portal for the purpose of private study or research.

- You may not further distribute the material or use it for any profit-making activity or commercial gain

- You may freely distribute the URL identifying the publication in the public portal 
${ }^{*}$ Corresponding author: Panagiotis

G. Kougias,

14 Engineering, Technical University of Denmark, Bld 113, 2800 Lyngby, Denmark.

15 E-mail address: panak@env.dtu.dk, Tel.: +45 45251454 


\section{Abstract}

A mixture of piggery slurry and algal species (mainly composed of

Nannochloropsis limnetica), grown in municipal wastewater, were used as substrates

19 for biogas production. Mono- and co-digestion experiments were performed at batch

20 and continuous reactor operation. The mono-digestion of wastewater microalgae led to

21 the highest methane yield (408 $\pm 34 \mathrm{NmL} / \mathrm{gVS}$ ). However, for manure-based biogas plants, a 60:40 v/v piggery slurry to wastewater microalgae ratio in terms of organic matter was identified as the most efficient mixture in batch assays $(355 \pm 27$ $\mathrm{NmL} / \mathrm{gVS}$ ). The advantage of co-digestion was also evidenced under continuous reactor operation, which had markedly higher biogas production $(23 \%, \mathrm{p}<0.05)$ compared to the mono-digestion of livestock manure. Moreover, it was demonstrated that the codigestion process resulted in a more robust process as indicated by lower accumulation of acetate (i.e. presented during mono-digestion of piggery slurry) and propionate (i.e. recorded during mono-digestion of wastewater microalgae). The experimental data were compared with dynamic modelling (BioModel). A new set of biodegradability parameters was estimated and employed to improve the simulations of mono-digestion scenarios. Subsequently, the co-digestion scenario was used for model validation. Results obtained from simulations showed that the co-digestion can lead to relatively high methane productivity and prevent process instabilities.

\section{Keywords}

37 Wastewater microalgae; piggery slurry; anaerobic digestion; biogas; methane; modelling 


\section{Introduction}

Anaerobic digestion (AD) of cultivated land-based biomass and especially, the usage of first generation biofuels (e.g. food crops) is steadily reduced due to the imperative need of producing food for the rising world population. On the other hand, second (e.g. wastes and residues) and third (e.g. algae) generation substrates can efficiently support the strong need for providing organic matter to the increased number of biogas plants [1].

Focusing on the second generation biofuels, the policy makers promote livestock manure as a basic substrate for full-scale applications by granting subsidies [2]. In addition, manures have several advantages for biogas production; they are available in large quantities, have high buffer capacity and can provide the digesters with all the micro- and macro-nutrients needed as well as essential microbes for an efficient AD process [3,4]. Also, biogas plants provide storage capacity for manures during rainy periods before they can be applied as bio-fertilisers, in order to limit nutrients wash-out.

54 Thus, manures are already used as a main organic matter provider to farm-scale and centralised biogas plants. For example, piggery wastewaters are consistently used as feedstock in numerous full-scale AD plants in Europe [5]. However, this particular livestock slurry is not recommended as a sole substrate due to its low volumetric methane potential [6] and increased risk for process failure due to ammonia toxicity [7]. Hence, co-digestion of piggery slurry with substrates that have dissimilar chemical composition is typically followed to overcome the technical challenges [8].

Among alternatives, third generation feedstocks are lately considered as a potential source of biomass. For example, algal biomass has some advantages compared to the alternative first and second generation substrates (e.g. annual growth, high growth rate, 
64 high theoretical methane potential, no need for either herbicides or pesticides) $[9,10]$. In 65 addition, cultivation of microalgae in industrial wastewaters has an important environmental benefit due to carbon dioxide fixation [11,12].

The integration of the aforementioned substrates in the feedstock of biogas reactors was previously examined in the literature. However, contradictory conclusions were drawn by comparing the outcomes of different studies. For example, Mahdy et al. [13] examined the co-digestion of cattle manure and microalgae under high ammonium levels and a synergistic effect of enriched feedstock was revealed. Based on the results, $80 \%$ share of microalgae on organic matter basis was recommended in order to increase the methane output under both biochemical methane potential (BMP) tests and continuous mode experiments. On the contrary, González-Fernández et al. [6] found that the BMP value of swine manure was significantly higher than the corresponding methane yield of microalgae biomass. Based on González-Fernández et al. [6], the hardly degradable cell walls of microalgae acted as a shield protecting from enzymatic hydrolysis; in contrast, swine manure is an easier substrate for anaerobic biodegradation. On this concept, to overcome the limited methanation of algal biomass, the co-digestion with swine manure was examined, and indeed, the methane production was increased due to the co-substrate addition.

It is well known that a universal co-digestion strategy does not exist and the energy output is significantly affected by various parameters such as biochemical substrate characteristics, operational conditions, microbial communities and reactor configurations [14]. Thus, linking these variables with process monitoring (e.g. methane productivity, $\mathrm{pH}$ and accumulation of intermediates) can be extremely helpful to optimize substrates utilisation and to identify feedstock mixtures that enhance biogas 
88 production. On this concept, simulation of experimental datasets using dynamic

89 bioconversion modelling can markedly improve the microalgae-based AD performance

90 [15]. Subsequently, the optimum feeding strategy can be defined focusing on both

91 bioenergy yield improvement and avoidance of instabilities, e.g. due to ammonia or

92 volatile fatty acids (VFA) accumulation.

93 The overall aim of the present study was to optimise the co-digestion process of 94 microalgae and piggery slurry. This was investigated experimentally through mono- and 95 co-digestion tests using both batch and continuously fed biogas reactors. Subsequently, 96 the results from continuous mode experiments were validated using the BioModel [16] 97 and the model simulation outputs were used to point out the most suitable feedstock 98 composition.

\section{Materials and methods}

101

\subsection{Inoculum and substrate}

102 Well-digested anaerobic sludge was collected from the effluent tank of a centralized

103 biogas plant (Snertinge, Denmark) and used as inoculum. The biogas plant treated 104 animal slurry (approximately two third of pig manure and one third of cattle slurry) 105 under thermophilic conditions. The inoculum was stored for 10 days in a thermophilic 106 incubator in order to deplete the biomethanation from the residual biodegradable 107 organic material.

108 The piggery slurry was collected from Lemvig biogas plant (Midtjylland, Denmark).

109 After arrival to the laboratory, the slurry was sieved (5 mm) in order to discard large 110 particles. Microalgae, which were grown in municipal wastewater (denoted as 111 wastewater microalgae), were provided from municipality of Kalundborg (Sealand, 
112 Denmark). The algal biomass consisted of mixed algal species (mainly composed of

113 Nannochloropsis limnetica). Both substrates were placed at $-20{ }^{\circ} \mathrm{C}$ for storage and

114 thawed at $4{ }^{\circ} \mathrm{C}$ for two days prior to their usage. The major characteristics of inoculum,

115 piggery slurry and wastewater microalgae are presented in Table 1.

116

117 Table 1. Characteristics of inoculum, piggery slurry and wastewater microalgae

\begin{tabular}{lccc}
\hline Characteristics & Inoculum & $\begin{array}{c}\text { Piggery } \\
\text { slurry }\end{array}$ & $\begin{array}{c}\text { Wastewater } \\
\text { microalgae }\end{array}$ \\
\hline pH & 8.21 & 8.50 & 5.87 \\
Total Solids (TS), g/L & $21.56 \pm 1.08$ & $33.50 \pm 1.68$ & $24.60 \pm 1.23$ \\
Volatile Solids (VS), g/L & $19.92 \pm 1.00$ & $21.79 \pm 1.09$ & $20.95 \pm 1.05$ \\
Carbohydrates, g/L & $16.86 \pm 0.84$ & $6.53 \pm 0.33$ & $8.19 \pm 0.41$ \\
Proteins, g/L & $2.25 \pm 0.11$ & $7.63 \pm 0.38$ & $10.00 \pm 0.50$ \\
Lipids, g/L & $0.01 \pm 0.00$ & $0.12 \pm 0.01$ & $2.63 \pm 0.13$ \\
Total Kjeldahl Nitrogen (TKN), g/L & $2.66 \pm 0.13$ & $4.31 \pm 0.22$ & $1.78 \pm 0.09$ \\
Ammonium Nitrogen (NH $\left.\mathbf{4}_{\mathbf{4}}^{+} \mathbf{N}\right), \mathbf{g} / \mathbf{L}$ & $2.57 \pm 0.13$ & $3.09 \pm 0.15$ & $0.18 \pm 0.01$ \\
Total Volatile Fatty acids (TVFA), & $0.79 \pm 0.04$ & $6.33 \pm 0.32$ & $0.13 \pm 0.01$ \\
g/L & & & \\
\hline
\end{tabular}

118

\subsection{Experimental set up}

120 Methane yield tests were performed to define the methane production of wastewater

121 microalgae and piggery slurry under mono- and co- digestion experiments, following

122 the guidelines of the standard protocol [17]. Regarding the co-digestion experiments,

123 the co-substrates were examined in VS-ratios of 80:20, 60:40, 40:60 and 20:80 in the

124 feedstock. The experimental sets were conducted at thermophilic conditions $\left(53 \pm 1^{\circ} \mathrm{C}\right)$

125 due to the several advantages that this temperature range offers compared to mesophilic

126 [18]. The total and working volume of the batch reactors were 337 and $100 \mathrm{~mL}$, 
127 respectively. In batch reactors the inoculum occupied $80 \%$ of the working volume (i.e.

$12880 \mathrm{~mL}$ ) and the initial organic load was set at $2 \mathrm{gVS} / \mathrm{L}$. The reactors were flushed with

129 nitrogen gas and sealed with rubber stoppers and aluminium screw caps in order to

130 ensure anaerobic conditions. The biogas production was monitored twice a week in

131 replicate samples. The methane yield was calculated at standard temperature and

132 pressure conditions based on the initial content of organic matter (i.e. NmL/gVS).

133 The continuous mode operation was evaluated in three continuously stirred tank

134 reactor (CSTRs), denoted as R1, R2 and R3. The first reactor (R1) was fed exclusively

135 with piggery slurry while wastewater microalgae was the sole substrate of R2. The third

136 reactor (R3) was co-digesting piggery slurry and wastewater microalgae in a VS-ratio of

137 60:40. As it will be further discussed, this mixture ratio was chosen on basis of the

138 results from the batch assay. The reactors had a total and working volume of 1000 and

$139750 \mathrm{~mL}$, respectively. The hydraulic retention time (HRT) was set at 15 days by feeding

140 the CSTRs once a day with $50 \mathrm{~mL}$ using peristaltic pumps. The organic loading rate

141 (OLR) was $1.4 \mathrm{gVS} / \mathrm{L} / \mathrm{d}$ during the whole experimental period. The influent bottles

142 were equipped with magnetic stirring devices and turned on 15 minutes before the

143 feeding in order to homogenize the entering substrates. In addition, the CSTRs were

144 equipped with a magnet and placed on the top of stirring devices to ensure the

145 homogeneity of working volume and avoid the formation of dead zones. Thermophilic

146 conditions $\left(53 \pm 1^{\circ} \mathrm{C}\right)$ were achieved by covering the CSTRs with electrical thermal

147 jackets. The temperature was monitored using a submerged probe into the CSTRs'

148 working volume. The biogas production was quantified daily by the water displacement

149 method using calibrated gas meters and gas counters [19]. The biogas composition, $\mathrm{pH}$

150 and VFA accumulation were analysed twice a week. All measurements were conducted 
in triplicate samples.

152

153

\subsection{Modelling and simulation approach}

\subsubsection{BioModel description}

The dynamic model (BioModel) developed by Angelidaki et al. [20] was used to investigate the mono and co-digestion scenarios in this work. The BioModel distinguishes three enzymatic pathways: 1) hydrolysis of undissolved carbohydrates, 2) hydrolysis of undissolved proteins, and 3) hydrolysis of undissolved lipids, and eight bacterial groups: (1) glucose-fermenting acidogens, (2) lipolytic bacteria, (3) LCFA-

160 degrading acetogens, (4) amino acid-degrading acidogens, (5) propionate, (6) butyrate, (7) valerate-degrading acetogens, and finally (8) aceticlastic methanogens. The hydrolytic steps are modelled with first order kinetics whilst acidogenic, acetogenic and aceticlastic pathways are modelled with Monod growth kinetic, respectively. Furthermore, BioModel includes VFA inhibition of the hydrolytic steps, acetate inhibition of the acetogenic steps, free ammonia inhibition of the methanogenic step, and $\mathrm{pH}$ and LCFA inhibition of all biological steps. A detailed description of the equations and main pathways for anaerobic degradation of organic matter used in the BioModel is illustrated in Fig. S1.1 (Supplementary material).

170 metabolic steps and chemical components, as well as the collection of model output

171 variables was set up as described by Kovalovszki et al. [16] and integration of the 172 model ordinary differential equation system was performed using the MATLAB's ode15s solver. Numerical optimization of selected parameter values was performed with

174 the trust-region reflective algorithm of MATLAB's lsqcurvefit function, by fitting the 
175 experimental data with the simulation results and solving a nonlinear least squares 176 minimization problem. In addition, the 95\% confidence intervals of the estimated

177 parameters were defined using the nlparci function built in MATLAB and applying 178 nonlinear regression.

$180 \quad$ 2.3.2. BioModel simulation, calibration and validation

181 As starting point, the set of general parameters determined by Kovalovszki et al.

182 [16] together with the input conditions (substrate composition, process operation 183 variables) were used to simulate the mono-digestion of piggery slurry and wastewater 184 microalgae. This set of general parameters has been tested to describe satisfactorily 185 various co-digestion scenarios [16,21]. The biogas and methane productivities of both mono-digestion scenarios were used to perform model calibration so that BioModel 187 predictions could be improved.

188 In a first attempt, parameters related to biodegradability and hydrolysis rate of 189 carbohydrates, proteins and lipids were considered for model calibration based on 1) the 190 extent of biodegradability depends on substrate organic fraction composition and 2) 191 hydrolysis pathway is the rate limiting step during AD of organic residues [22]. 192 Nevertheless, the estimation of the hydrolysis kinetic parameters did not show a 193 significant improvement in the model calibration compared to biodegradability 194 parameters. Hence, the latter ones were finally used for the model calibration of the 195 mono-digestion scenarios. The parameter values were estimated numerically, 196 considering the experimental biogas and methane productivities (Table 2). The rest of 197 BioModel parameters were not modified.

198 The set of optimized biodegradability parameters from mono-digestion scenarios 
199 were then used for simulation of the co-digestion scenario piggery slurry (60\% VS) and 200 wastewater microalgae (40\% VS); and based on the quality of the prediction, these 201 parameters could be fitted again considering the experimental data set of the 202 corresponding co-digestion scenario. 
Table 2. Estimated parameters for mono-digestion and co-digestion scenarios

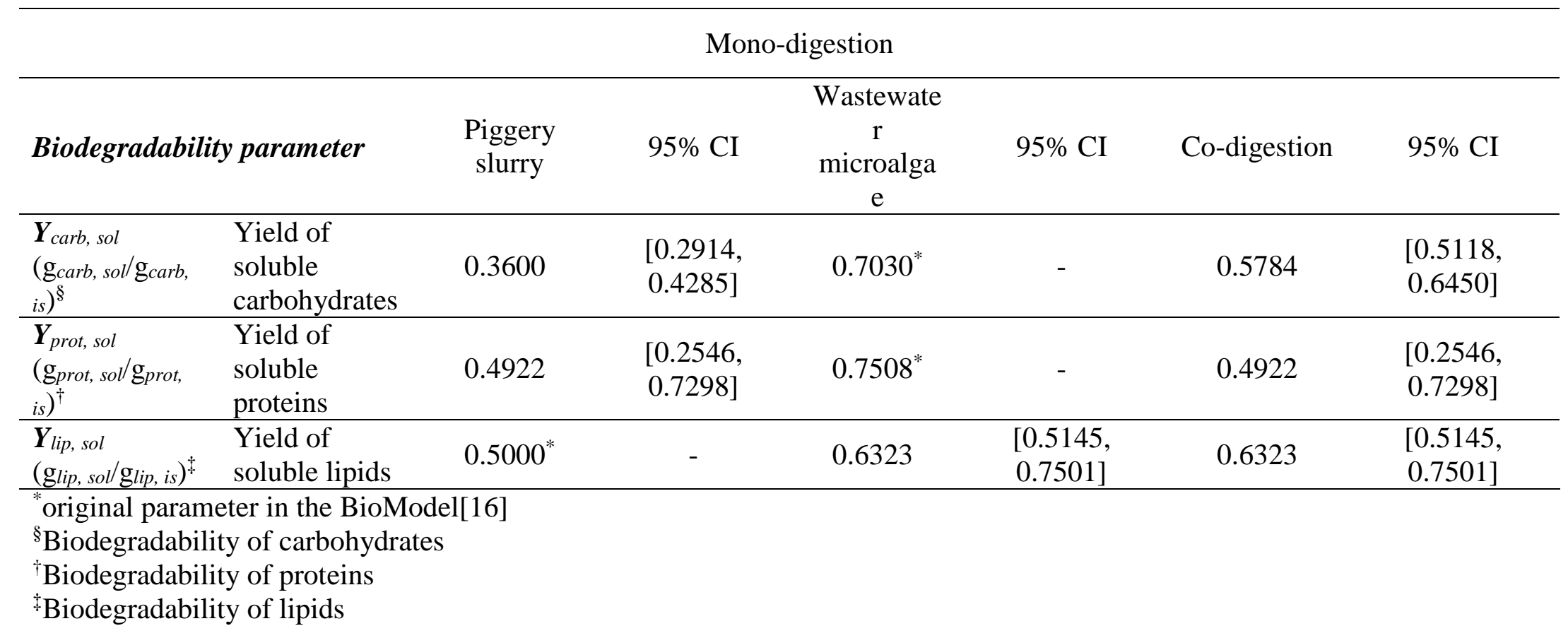




\section{2.4. Analytical methods}

2 Measurements of $\mathrm{pH}$, total solids (TS), volatile solids (VS), ammonium nitrogen

$3\left(\mathrm{NH}_{4}-\mathrm{N}\right)$ and total Kjeldahl nitrogen $(\mathrm{TKN})$ were conducted based on the guidelines of

4 Standard Methods [22]. The crude protein content was calculated by multiplying the

5 organic nitrogen by the factor of 6.25 [23]. Structural carbohydrates were detected and

6 quantified using high performance liquid chromatography (HPLC) based on Alvarado-

7 Morales et al. [24]. Lipid extraction was carried out according to Marinho et al. [25].

8 Gas chromatography (Shimadzu GC-2010, Japan) was used to determine the VFA

9 composition based on Kougias et al. [26]. The C:N ratios of piggery slurry and

10 wastewater microalgae were calculated using the elementary chemical composition. The

11 methane content in the headspace of batch assays was measured by gas chromatography

12 (Shimadzu GC-8A, Japan) as previously described [27]. For the continuous mode

13 experiment, the biogas composition was determined with a gas chromatograph

14 (Mikrolab, Aarhus A/S, Denmark), equipped with a thermal conductivity detector

15 (TCD). All the determinations were performed in triplicate.

\subsection{Statistical analysis}

OriginPro 9.0.0 SR2 software (OriginLab Corporation, USA) was used for data analysis. Descriptive statistics were conducted for all variables and standard deviations were calculated. For comparison of significant differences among the methane yield of

21 batch assays, as well as experimental data obtained during CSTR monitoring, analysis of variance (ANOVA) was carried out followed by Tukey Post-Hoc Analysis ( $<<0.05)$. 


\subsection{Synergy or antagonism}

To reveal potential synergistic or antagonistic effects occurred during the $\mathrm{AD}$ process, the following Equation was used:

$$
n=\frac{\text { Practical yield }}{\text { Predicted yield }}
$$

The "Practical yield" is the experimentally measured methane yield for each codigestion mixture. The "Predicted yield" is the calculated methane yield based on the values obtained by the mono-digestion tests. The result of $n$ shows:

- $n>1$, synergistic effect

- $n=1$, no effect

- $n<1$, antagonistic effect

\section{Results and discussion}

\subsection{AD experiments}

\subsubsection{Batch assays}

Methane yield tests at a specific organic load were performed in order to: 1) determine the methane potential of both piggery slurry and wastewater microalgae; 2) define possible synergistic effect during the co-digestion process (Fig. 1). The lowest methane yield was measured for the mono-digestion of piggery slurry (255 \pm 65 $\mathrm{NmL} / \mathrm{gVS}$ ). Indeed, this type of wastewater typically leads to low methane production mainly due to its high ammonia content. It has been previously reported that the containing free ammonia diffuses into microbial cells and cause stress conditions[23].

44 Regarding co-digestion, the partial replacement of animal slurry with wastewater microalgae enhanced the biomethanation under all enriched feedstocks. Especially, the highest methane yield was succeeded when the share of piggery slurry in the feeding 
mixture was $60 \%$ in terms of organic matter (355 $\pm 27 \mathrm{NmL} / \mathrm{gVS})$, revealing a synergistic effect on the methane productivity equal to $12 \%$. Overall, the results from methane yield tests indicated that the co-digestion poses the ability to increase the low methane yield of slurry's mono-digestion. In order to validate this result, the codigestion effect was investigated in continuously fed reactors so as to monitor the process in long-term operation. More specifically, both substrates' mono-digestion and the co-digestion mixture $(60: 40)$ with the highest methane yield were examined using CSTRs.

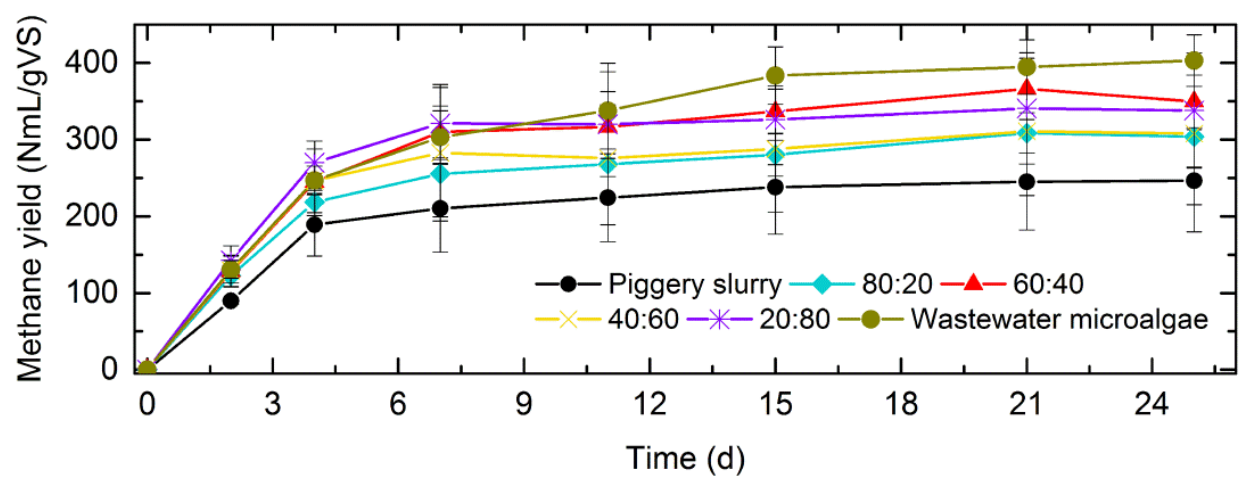

Fig. 1. Methane development plotted against time for the AD of piggery slurry and wastewater microalgae. The co-digestion mixtures represent the share of organic matter between the two substrates (piggery slurry: wastewater microalgae).

\subsubsection{Continuous reactor operation}

To further evaluate the mono- and co-digestion of piggery slurry and wastewater microalgae, three CSTRs fed with different feedstocks were monitored until steady state conditions were established (i.e. stable biogas production with lower than $10 \%$ daily

64 variation for a period at least 10 days) [31]. R1 treated piggery slurry as sole substrate and was associated with the lowest bioenergy output, which is in agreement with the results from methane yield experiments (Fig. 2). 


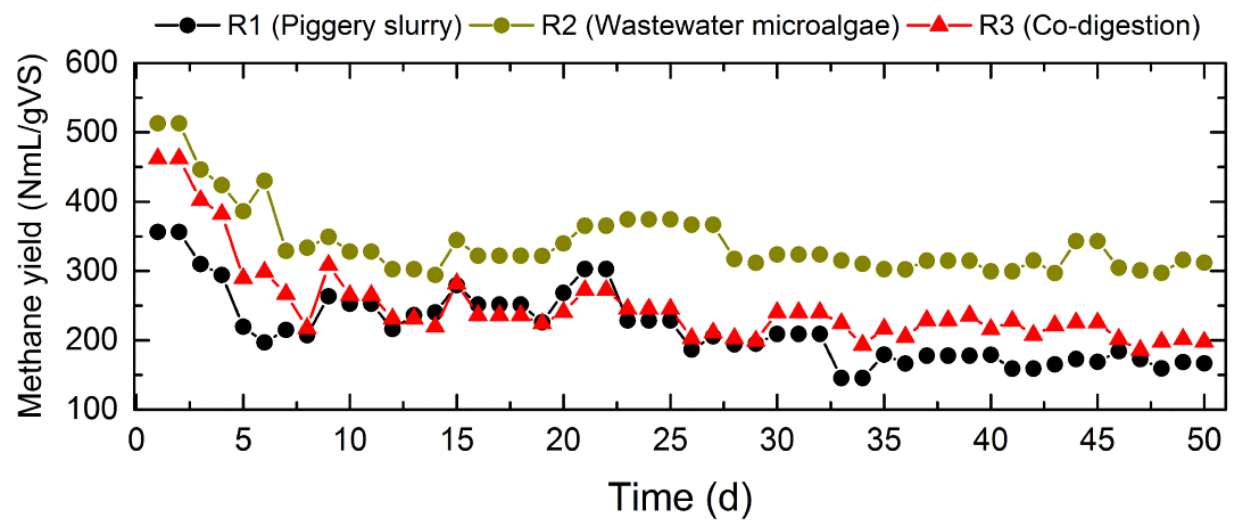

Fig. 2. Methane yield in mono-digestion of piggery slurry (R1), wastewater microalgae (R2) and the co-digestion at 60:40 contribution of organic matter (R3).

In fact, a higher dilution could have revealed the ultimate BMP value as the inoculum would dilute the ammonia to non-inhibitory levels. However, this was not the aim of the present study as the methane yield test was focused on specific conditions. On the contrary, the usage of wastewater microalgae led to significantly higher ( $\mathrm{p}<$ 0.05) bioenergy output (408 $\pm 34 \mathrm{NmL} / \mathrm{gVS}$ ) compared to the animal slurry. The augmented methane output can be attributed to the increased carbohydrates which are relatively easy to be anaerobically degraded [28] and to the higher lipids content which have high theoretical methane potential [29]. The obtained methane yield of wastewater microalgae is within the literature values for both pure Nannochlorospsis sp. (340-414 NmL/gVS) and wastewater consortia (303-347 NmL/gVS) [30].

Despite the limited performance, stable biomethanation was recorded after two HRTs. Before start-up, the CSTRs were filled with effluent from a biogas plant that was fed with swine manure as major substrate. Therefore, the AD microbiome was adapted to the examined substrate and thus, it should have been able to process efficiently the nitrogenous substrate [32].

However, it was previously shown that this type of waste frequently leads to 
86 inhibited steady state conditions which is a "pseudo steady-state" often seen with 87 ammonia rich substrates [33]. In accordance, limited process performance was revealed 88 during the current experiment through the low methane production and the 89 accumulation of VFA (Fig. 3f). Free ammonia $\left(\mathrm{NH}_{3}\right)$ is considered as the inhibiting 90 form of ammonia $\left(\mathrm{NH}_{3}+\mathrm{NH}_{4}^{+}\right)$which is increasing along $\mathrm{pH}$ and temperature. 91 However, the pH values which directly affect the free ammonia concentration were 92 relatively stable, indicating that an alleviation from ammonia toxicity did not occur 93 [34].
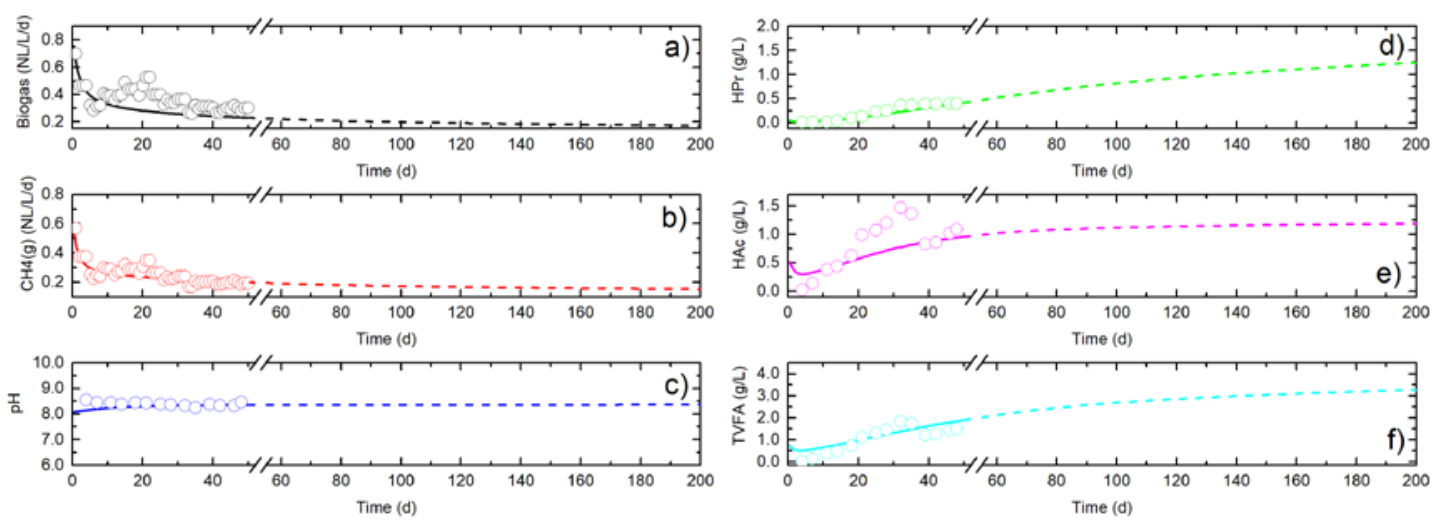

94

Fig. 3. Comparison between experimental values (open circles) and data obtained from BioModel simulations estimated parameters (straight lines) for the mono-digestion of piggery slurry (R1). Dashed lines indicate simulations of post-experimental period with estimated parameters.

The AD of wastewater microalgae as sole substrate was examined in R2. Increased biomethanation was established and at steady state conditions the methane yield reached $313 \pm 13 \mathrm{NmL} / \mathrm{gVS}$, corresponding to approximately $77 \%$ of the expected energy output based on methane yield tests. Similarly, Mahdy et al. [13] found that the monodigestion of microalgae was associated with comparable methane production (approximately 320 NmL/gVS) under continuous mode operation. Despite the markedly 
105 high methane production, an undesired increasing trend of propionate accumulation was 106 observed at the end of the present experimental research (Fig. 4d). Accordingly, the

107 concentration of propionate is considered as a state indicator for AD process imbalance

108 [35]. Propionate is persistent for $\mathrm{AD}$ and accumulation in long duration can lead to $\mathrm{pH}$

109 decrease and subsequently, to potential process failure which is a major bottleneck from

110 an industrial point of view.
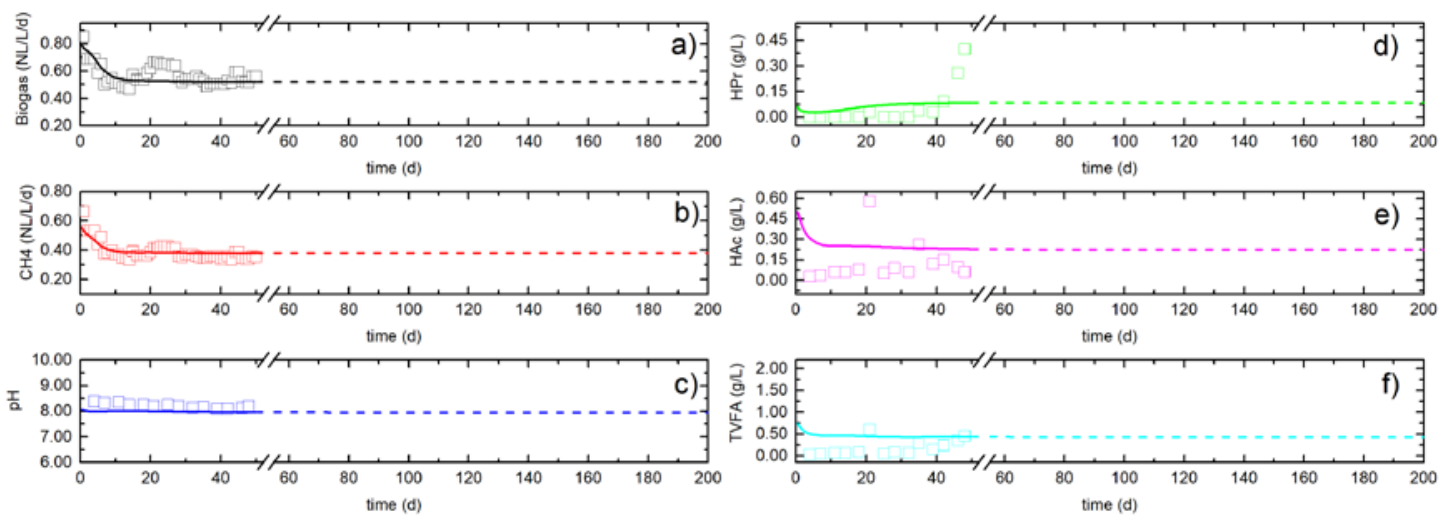

111

112 Fig. 4. Comparison between experimental values (open squares) and data obtained from

113 BioModel simulations with estimated parameters (straight lines) for the mono-digestion

114 of wastewater microalgae (R2). Dashed lines indicate simulations of post-experimental

115 period with estimated parameters.

116 Furthermore, wastewater microalgae cannot be widely considered as a main

117 feedstock for full-scale applications, because of their low substrate availability and also,

118 proximity to the biogas plants is not always ensured for this type of feedstock. In

119 contrast, large amounts of livestock wastewater are easily available within the

120 agricultural sector [36]. In this context, the co-digestion with livestock slurry is a rather

121 more realistic strategy for full-scale implementation. Moreover, the buffer capacity of

122 the system can be increased and the microbiome be enriched with more diverse

123 members that could positively alleviate the aforementioned weaknesses and 
124 consequently, boost the AD performance.

125 The results from the co-digestion reactor (R3) showed negligible accumulation of

126 propionate or other intermediate compounds in contrast to R1 and R2, during the whole 127 experimental period. In addition, after two HRTs the total VFAs were at low levels, 128 indicating a well-functioning process [37]. Similarly to batch assays, the continuous 129 mode operation of co-digestion led to higher bioenergy production (216 \pm 17 $130 \mathrm{NmL} / \mathrm{gVS})$ than the mono-digestion of piggery slurry (176 $\pm 18 \mathrm{NmL} / \mathrm{gVS})$.

131 Specifically, the methane yield was significantly higher $(23 \%$, p $<0.05)$ than the 132 corresponding one from the degradation of the nitrogenous substrate. In addition, the 133 achieved methane yield during continuous reactor operation was approximately $68 \%$ of 134 the ultimate value based on batch assays. Compared to livestock's slurry mono135 digestion, the $\mathrm{pH}$ was slightly lower and thus, the free ammonia concentration had 136 decreased values at steady conditions $(<0.5 \mathrm{~g}-\mathrm{N} / \mathrm{L})$. Additionally, it was previously 137 concluded that substrates with increased lipid content, like the wastewater microalgae, 138 could alleviate the digester from the toxicity of nitrogenous co-substrate [20]. Hence, 139 process instabilities were avoided and the positive effect of utilizing dissimilar 140 substrates was revealed.

\section{$142 \quad$ 3.2. Simulation results}

143 3.2.1. Model simulation and calibration

144 As shown in Fig. 3 and 4, the BioModel with the default parameters exhibited a 145 good performance in describing the experimental trend of both mono-digestion 146 scenarios. However, with the new set of parameters, the experimental trend is better 147 captured during steady state period, particularly for the $\mathrm{pH}$, biogas and methane flow 
148 rates. The set of estimated parameters was used to perform further simulations in order

149 to investigate the process performance of the three scenarios after the experimental 150 period (50 days).

151 For the case of piggery slurry mono-digestion (R1), biogas and methane

152 productivities were well captured by the model (straight black and red lines) during the

153 entire experimental period (Fig. 3a-b). However, biogas productivities were slightly

154 underestimated between days 15-30. In addition, acetic acid concentrations were

155 underestimated between days 25-35, though after this the model predicts the

156 experimental trend. The model predicted a low intermediates' concentration trend

157 during the start-up period, to subsequently increase, leading to the accumulation of

158 VFAs (Fig. 3d-f). Eventually VFA concentration stabilized, reaching a steady state

159 (blue dash line) value of 2.02 g/L (Fig. 3f). This is explained by simulation results,

160 where a slight increase in free ammonia concentration is observed during the adaptation

161 period reaching a maximum at 0.85 g-N/L (Fig. 5a), which can slow down the

162 methanogenic activity leading to VFA accumulation [38], although not being a critical

163 cause of process failure. In parallel, the $\mathrm{pH}$ level was also changed to more alkaline

164 conditions (i.e. from 8.07 to 8.26), shifting the equilibrium from $\mathrm{NH}_{4}^{+}$towards $\mathrm{NH}_{3}$

165 formation [39]. However, due to the buffer capacity of the system this effect is

166 counteracted and thus, free ammonia concentration decreased to 0.80 g-N/L leading to a

167 stable performance of the reactor in the long-term operation (Fig. 5a). The $\mathrm{pH}$ also

168 became stable at 8.32; a value that is consistent with the experimental trend from day 32

169 and onward (Fig. 3c).

170 As noticed after the experimental period, the trend of both methane and biogas

171 shows a slight decrease over time whilst VFA concentration shows the opposite trend 
172 (Fig. 3a, b, d-f). Therefore, in order to investigate whether or not the accumulation of

173 VFA might have a detrimental effect in biogas and methane production over time, a

174 simulation was performed until the system reached steady state (data not shown). Total

175 VFA and TAN steady state concentrations corresponded to $3.85 \mathrm{~g} / \mathrm{L}$ and $2624 \mathrm{mg}-\mathrm{N} / \mathrm{L}$,

176 respectively. This TAN concentration is within the inhibitory range (1500-7000

$177 \mathrm{mg} / \mathrm{L})[40]$. On the other hand, biogas and methane productivities decreased to 0.147

178 and $0.131 \mathrm{NL} / \mathrm{L} / \mathrm{d}$, respectively. This might be an indication that in the long-term

179 operation, the system could reach the so called "inhibited steady state [33]".

180
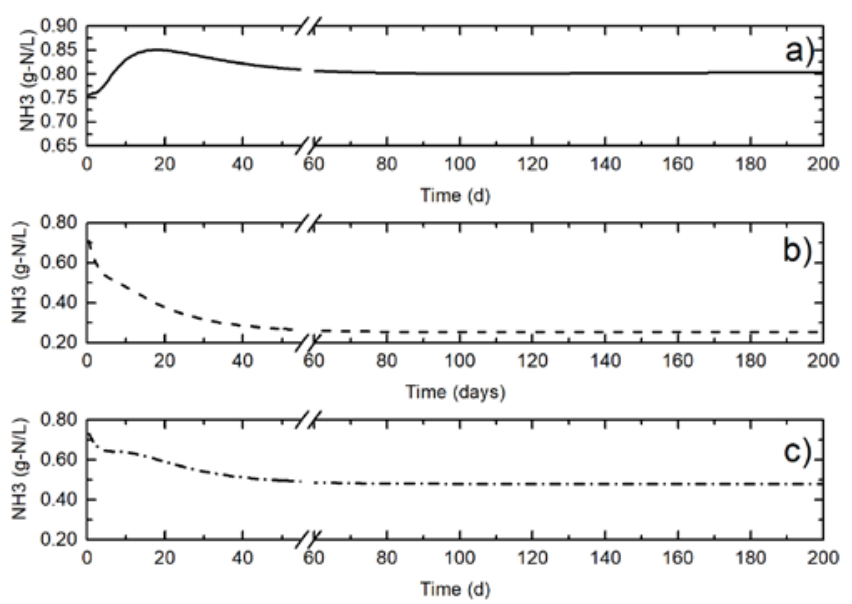

181 Fig. 5. Simulation results for free ammonia composition: a) mono-digestion of piggery

182 slurry, b) mono-digestion of wastewater microalgae and c) co-digestion of wastewater 183 microalgae and piggery slurry.

184 Likewise, for the mono-digestion of wastewater microalgae (R2) biogas and 185 methane productivities were also well captured by the updated model (straight lines) as 186 observed in Fig. 4a-b; although the model could not capture the experimental trend 187 between days 21-27 for biogas productivity. VFA process dynamics were slightly 188 overestimated (Fig. 4d-f) and specifically, the observed trend in the accumulation of propionate starting from day 40 could not be captured by the model. In spite of the rapid 
190 increase in propionate concentration at day 40, both biogas and methane productivities 191 were kept stable until the end of the experimental period. It is known that the

192 accumulated intermediates could lead to reactor acidification and process failure in 193 long-term operation [41]. However, simulation results after the experimental period 194 revealed that no further intermediate accumulation took place, keeping VFA below the 195 levels considered harmful for process stability [42]. In addition, process simulation 196 results showed a decrease in free ammonia concentration from 0.72 to $0.24 \mathrm{~g}-\mathrm{N} / \mathrm{L}$ over 197 the complete experimental period (Fig. 5b). This observation is consistent with the drop 198 in $\mathrm{pH}$ exhibited by both experimental results and model simulations. Along with the 199 aforementioned, simulation results for the post-experimental period show a stable long200 term operation of the system.

201

202

3.2.2. Simulation of co-digestion scenario and model validation

203

Results of the co-digestion experiment were used for model validation. At this point,

204 the biodegradability parameter of carbohydrates was fitted, whilst the protein and lipid 205 biodegradability parameters were the same as for the mono-digestion scenarios (Table 206 2). Biogas and methane productivities were predicted quite well (Fig. 6a-b) and only a 207 slight overestimation in the case of methane was observed. As depicted in Fig. 6d, 208 dynamics for propionate were well predicted during the adaptation period until day 32. 209 Afterwards, the simulated concentration of propionate remained stable $(0.12 \mathrm{~g} / \mathrm{L})$ in 210 contrast to the experimental trend (dropping from 0.11 to $0.02 \mathrm{~g} / \mathrm{L}$ ). In the case of 211 acetate, process dynamics were not accurately captured during the start-up process, but 212 were adequately predicted from day 35 and onward, where the estimated concentrations 213 were in agreement with the experimental trend. 
215 inhibitory thresholds to cause potential process failure. This indicates stable digester

216 performance and good synergistic activities of acidogenic and methanogenic

217 microorganisms [43], in contrast to the mono-digestion of piggery slurry (R1).

218 Furthermore, simulation results after the experimental period showed that the long-term

219 co-digestion of piggery slurry and wastewater microalgae did not promote the 220 accumulation of VFA. Similarly to the low VFA accumulation, simulation results also 221 revealed that free ammonia concentration was below critical levels $(<1.1 \mathrm{~g}-\mathrm{N} / \mathrm{L})$ for 222 inhibition or toxicity problems in the $\mathrm{AD}$ system [44,45]. Lastly, the findings also 223 showed the advantage in performing co-digestion of dissimilar substrates, in order to 224 avoid process failure.
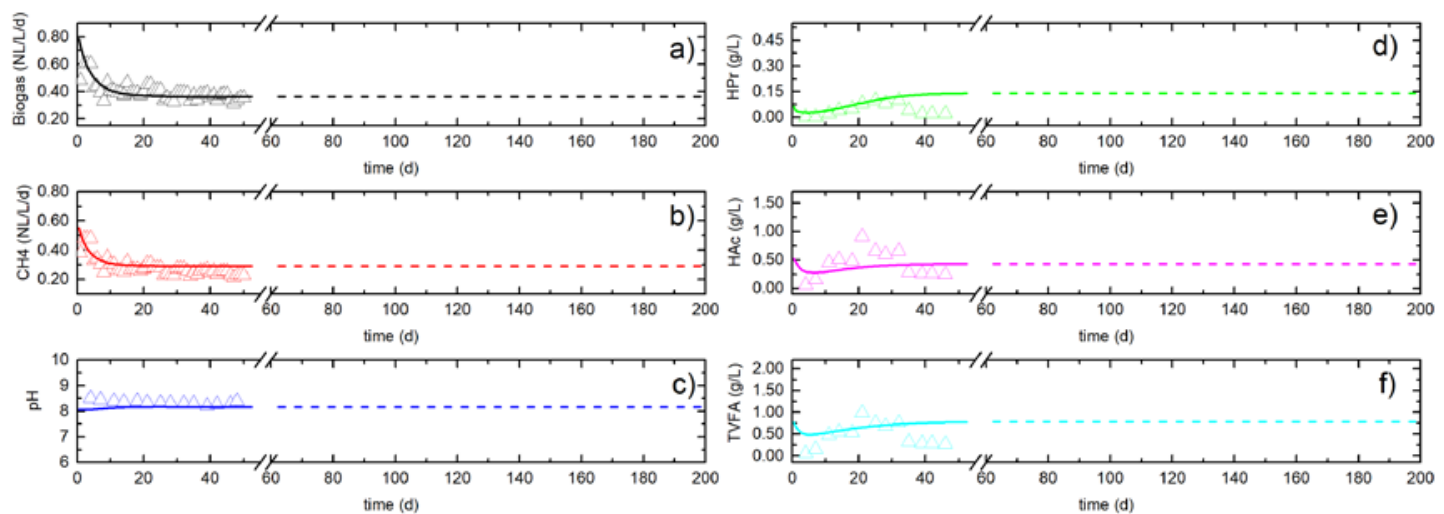

225

Fig. 6. Model validation for the co-digestion of wastewater microalgae and piggery slurry: simulation (straight lines) vs experimental data (open triangles).

\section{Conclusions}

230 The present study demonstrated that the anaerobic digestion of wastewater microalgae can lead to relatively high methane production. The benefit of using 
and continuous mode operation. In addition, the positive effect of using two dissimilar,

234 yet complementary waste streams for biogas production was clearly shown.

235 Specifically, the partial replacement of piggery slurry with wastewater microalgae by

$23640 \%$ in terms of organic matter in the influent feedstock improved the bioenergy

237 production by 23\%. Moreover, the applicability of the BioModel to efficiently simulate

238 both mono- and co-digestion strategies was revealed. In addition, the simulations

239 indicated that the long-term co-digestion of second and third generation substrates is

240 associated with high gas productivity and absence of inhibition risks due to ammonia or

241 volatile fatty acid accumulation.

\section{Acknowledgements}

The authors thank Hector Garcia for technical assistance. This work was fully supported

by ForskEL Project 12197 “Improving Synergy and Robustness of the Manure Codigestion Process”.

\section{References}

[1] E. Allen, D.M. Wall, C. Herrmann, J.D. Murphy, A detailed assessment of resource of biomethane from first, second and third generation substrates, Renew. Energy. 87 (2016) 656-665.

[2] M. Shafiei, M.M. Kabir, H. Zilouei, I. Sárvári Horváth, K. Karimi, Technoeconomical study of biogas production improved by steam explosion pretreatment., Bioresour. Technol. 148 (2013) 53-60.

[3] I.A. Fotidis, P.G. Kougias, I.D. Zaganas, T.A. Kotsopoulos, G.G. Martzopoulos, Inoculum and zeolite synergistic effect on anaerobic digestion of poultry manure., Environ. Technol. 35 (2013) 1219-25.

[4] B. Molinuevo-Salces, B.K. Ahring, H. Uellendahl, Optimization of the CoDigestion of Catch Crops with Manure Using a Central Composite Design and Reactor Operation, Appl. Biochem. Biotechnol. 175 (2014) 1710-1723.

[5] G.J. Escobar, M.A. Heikkilä, "Biogas production in farms , through anaerobic digestion of cattle and pig manure . Case Studies and research activities in Europe,” TEKES, OPET Finl. (1999).

[6] C. González-Fernández, B. Molinuevo-Salces, M.C. García-González, 
[7] P. Ferrer, M. Cambra-López, A. Cerisuelo, D.S. Peñaranda, V. Moset, The use of

[8] P.G. Kougias, T. Kotsopoulos, G.G. Martzopoulos, Effect of feedstock composition and organic loading rate during the mesophilic co-digestion of olive mill wastewater and swine manure, Renew. Energy. 69 (2014) 202-207.

[9] S. Behera, R. Singh, R. Arora, N.K. Sharma, M. Shukla, S. Kumar, Scope of algae as third generation biofuels., Front. Bioeng. Biotechnol. 2 (2014) 90.

[10] O.K. Dalrymple, T. Halfhide, I. Udom, B. Gilles, J. Wolan, Q. Zhang, S. Ergas, Wastewater use in algae production for generation of renewable resources: a review and preliminary results., Aquat. Biosyst. 9 (2013) 2.

[11] I. Udom, B.H. Zaribaf, T. Halfhide, B. Gillie, O. Dalrymple, Q. Zhang, S.J. Ergas, Harvesting microalgae grown on wastewater, Bioresour. Technol. 139 (2013) 101-106.

[12] M.P. Caporgno, A. Taleb, M. Olkiewicz, J. Font, J. Pruvost, J. Legrand, C. Bengoa, Microalgae cultivation in urban wastewater: Nutrient removal and biomass production for biodiesel and methane, Algal Res. 10 (2015) 232-239.

[13] A. Mahdy, I.A. Fotidis, E. Mancini, M. Ballesteros, C. Gonzalez-Fernandez, I. Angelidaki, Ammonia tolerant inocula provide a good base for anaerobic digestion of microalgae in third generation biogas process, Bioresour. Technol. 225 (2017) 272-278.

[14] T. Fitamo, A. Boldrin, G. Dorini, K. Boe, I. Angelidaki, C. Scheutz, Optimising the anaerobic co-digestion of urban organic waste using dynamic bioconversion mathematical modelling, Water Res. 106 (2016) 283-294. doi:10.1016/j.watres.2016.09.043.

[15] F. Passos, R. Gutierrez, D. Brockmann, J.P. Steyer, J. Garcia, I. Ferrer, Microalgae production in wastewater treatment systems, anaerobic digestion and modelling using ADM1, Algal Res. 10 (2015) 55-63.

[16] A. Kovalovszki, M. Alvarado-Morales, I.A. Fotidis, I. Angelidaki, A systematic methodology to extend the applicability of a bioconversion model for the simulation of various co-digestion scenarios, Bioresour. Technol. 235 (2017) 157-166.

[17] I. Angelidaki, M. Alves, D. Bolzonella, L. Borzacconi, J.L. Campos, A.J. Guwy, S. Kalyuzhnyi, P. Jenicek, J.B. Van Lier, Defining the biomethane potential (BMP) of solid organic wastes and energy crops: A proposed protocol for batch assays, Water Sci. Technol. 59 (2009) 927-934. doi:10.2166/wst.2009.040.

[18] P.G. Kougias, I. Angelidaki, Biogas and its opportunities - A review, 12 (2018).

[19] I. Angelidaki, L. Ellegaard, B.K. Ahring, Compact automated displacement gas metering system for measurement of low gas rates from laboratory fermentors, Biotechnol. Bioeng. 39 (1992) 351-353. doi:10.1002/bit.260390314.

[20] I. Angelidaki, L. Ellegaard, B.K. Ahring, A comprehensive model of anaerobic bioconversion of complex substrates to biogas, Biotechnol. Bioeng. 63 (1999) 363-372. doi:10.1002/(SICI)1097-0290(19990505)63:3<363::AIDBIT13>3.0.CO;2-Z.

[21] G. Lovato, M. Alvarado-Morales, A. Kovalovszki, M. Peprah, P.G. Kougias, 
J.A.D. Rodrigues, I. Angelidaki, In-situ biogas upgrading process: Modeling and simulations aspects, Bioresour. Technol. 245 (2017). doi:10.1016/j.biortech.2017.08.181.

[22] APHA, Standard Methods for the Examination of Water and Wastewater, Am. Water Work. Assoc. Public Work. Assoc. Environ. Fed. (2005). http://www.mendeley.com/research/standard-methods-examination-waterwastewater-169/ (accessed September 29, 2014).

[23] K.H. Hansen, I. Angelidaki, B.K. Ahring, Anaerobic Digestion of Swine Manure: Inhibition By Ammonia, Water Res. 32 (1998) 5-12.

[24] M. Alvarado-Morales, I.B. Gunnarsson, I. a. Fotidis, E. Vasilakou, G. Lyberatos, I. Angelidaki, Laminaria digitata as a potential carbon source for succinic acid and bioenergy production in a biorefinery perspective, Algal Res. 9 (2015) 126132. doi:10.1016/j.algal.2015.03.008.

[25] G.S. Marinho, S.L. Holdt, C. Jacobsen, I. Angelidaki, Lipids and composition of fatty acids of Saccharina latissima cultivated year-round in integrated multitrophic aquaculture, Mar. Drugs. 13 (2015) 4357-4374.

[26] P.G. Kougias, K. Boe, I. Angelidaki, Effect of organic loading rate and feedstock composition on foaming in manure-based biogas reactors, Bioresour. Technol. 144 (2013) 1-7.

[27] P.G. Kougias, K. Boe, P. Tsapekos, I. Angelidaki, Foam suppression in overloaded manure-based biogas reactors using antifoaming agents., Bioresour. Technol. 153 (2014) 198-205. doi:10.1016/j.biortech.2013.11.083.

[28] Y. Miron, G. Zeeman, J.B. Van Lier, G. Lettinga, The role of sludge retention time in the hydrolysis and acidification of lipids, carbohydrates and proteins during digestion of primary sludge in CSTR systems, Water Res. 34 (2000) 1705-1713.

[29] S. Park, Y. Li, Evaluation of methane production and macronutrient degradation in the anaerobic co-digestion of algae biomass residue and lipid waste, Bioresour. Technol. 111 (2012) 42-48.

[30] A.J. Ward, D.M. Lewis, F.B. Green, Anaerobic digestion of algae biomass: A review, Algal Res. 5 (2014) 204-214. doi:10.1016/j.algal.2014.02.001.

[31] S. Han, Y. Liu, S. Zhang, G. Luo, Reactor performances and microbial communities of biogas reactors: effects of inoculum sources, Appl. Microbiol. Biotechnol. 100 (2016) 987-995.

[32] M. Westerholm, J. Moestedt, A. Schnürer, Biogas production through syntrophic acetate oxidation and deliberate operating strategies for improved digester performance, Appl. Energy. 179 (2016) 124-135.

[33] F. Lü, L. Hao, D. Guan, Y. Qi, L. Shao, P. He, Synergetic stress of acids and ammonium on the shift in the methanogenic pathways during thermophilic anaerobic digestion of organics, Water Res. 47 (2013) 2297-2306.

[34] E. Uggetti, F. Passos, M. Sole, J. Garcia, I. Ferrer, Biogas from Algae via Anaerobic Digestion, in: Green Energy Technol., SPRINGER, 2016: pp. 195216.

[35] P. Tsapekos, P.G. Kougias, L. Treu, S. Campanaro, I. Angelidaki, Process performance and comparative metagenomic analysis during co-digestion of manure and lignocellulosic biomass for biogas production, Appl. Energy. 185 (2017) 126-135.

[36] J.B. Holm-Nielsen, T. Al Seadi, P. Oleskowicz-Popiel, The future of anaerobic 
digestion and biogas utilization., Bioresour. Technol. 100 (2009) 5478-84. doi:10.1016/j.biortech.2008.12.046.

[37] K. Boe, D.J. Batstone, J.-P. Steyer, I. Angelidaki, State indicators for monitoring the anaerobic digestion process, Water Res. 44 (2010) 5973-5980.

[38] D.T. Sponza, O.N. Ağdağ, Impact of leachate recirculation and recirculation volume on stabilization of municipal solid wastes in simulated anaerobic bioreactors, Process Biochem. 39 (2004) 2157-2165.

[39] J.M. Ayre, N.R. Moheimani, M.A. Borowitzka, Growth of microalgae on undiluted anaerobic digestate of piggery effluent with high ammonium concentrations, Algal Res. 24 (2017) 218-226. doi:10.1016/j.algal.2017.03.023.

[40] R. Rajagopal, D.I. Massé, G. Singh, A critical review on inhibition of anaerobic digestion process by excess ammonia, Bioresour. Technol. 143 (2013) 632-641. doi:10.1016/j.biortech.2013.06.030.

[41] T. Thamsiriroj, A.S. Nizami, J.D. Murphy, Why does mono-digestion of grass silage fail in long term operation?, Appl. Energy. 95 (2012) 64-76. doi:10.1016/j.apenergy.2012.02.008.

[42] I. Angelidaki, X. Chen, J. Cui, P. Kaparaju, L. Ellegaard, Thermophilic anaerobic digestion of source-sorted organic fraction of household municipal solid waste: Start-up procedure for continuously stirred tank reactor, Water Res. 40 (2006) 2621-2628. doi:10.1016/j.watres.2006.05.015.

[43] P. Weiland, Biogas production: Current state and perspectives, Appl. Microbiol. Biotechnol. 85 (2010) 849-860.

[44] I. Angelidaki, B.K. Ahring, Anaerobic thermophilic digestion of manure at different ammonia loads: Effect of temperature, Water Res. 28 (1994) 727-731.

[45] I. Angelidaki, B.K. Ahring, Thermophilic anaerobic digestion of livestock waste: the effect of ammonia, Appl. Microbiol. Biotechnol. 38 (1993) 560-564. 